Laura Bazzicalupo. Catedrática de Filosofía Política en el Dipartimento di Scienze Politiche, Sociali e della Comunicazione de la Università degli Studi di Salerno. Sus intereses científicos son las problemáticas de las tecnologías gubernamentales, los procesos de subjetivación y los dispositivos del poder bioeconómicos y biopolíticos. Entre sus últimas publicaciones, se encuentran: Bipolitica ed economia (Laterza, 2006); Superbia. La passione dell'essere (Il Mulino, 2008); Biopolitica una mappa concettuale (Carocci, 2010); Eroi della libertà (Il Mulino, 2011); Politica. Rappresentazioni e tecniche di governo (Carocci, 2013); Dispositivi e soggettivazioni (Mimesis, 2013).

Contacto: 1.bazzicalupo@unisa.it 


\title{
SALDAR CUENTAS CON EL PASADO: CONFLICTOS, MEDIACIONES Y JUSTICIA TRANSICIONAL
}

\author{
Laura Bazzicalupo
}

Università degli Studi di Salerno

\section{TO SETTLE SCORES WITH THE PAST: CONFLICTS, MEDIATIONS AND TRANSITIONAL JUSTICE}

DOI: $1017450 / 160201$

En este número, Soft Power recoge el desafío de los complicados procesos de transición que afectan a diferentes partes del mundo globalizado, interconectado e interdependiente, pero no pacificado. Es imposible agotar un tema tan complejo; mejor sería abrir un laboratorio de reflexión sobre estos procesos, cada uno de los cuales -cabe destacartiene características específicas y circunstanciales. Abrir un laboratorio significa abrir un espacio conceptual y analítico que nos permitirá volver más veces sobre las experimentaciones en curso y sobre los discursos de verdad subyacentes a los dispositivos de pacificación y reconciliación.

Para nuestra revista se trata de un desafío, porque es una temática que -en nuestra opinión- cita en juicio al soft power; es decir, se entera de la crisis en la que entra la teorización jurídica moderna cosmopolítica y la pretensión de que sea posible gestionar la transición a través de un conjunto de normas jurídicas generales y abstractas, 
tal y como el cosmopolitismo jurídico moderno deseaba ${ }^{1}$. El eje de nuestra revista se fundamenta, precisamente, en las formas de racionalidad política nueva en las prácticas de gobierno y gobernanza de la complejidad. Y se habla de realidades muy complejas cuando se trata de conflictos que solo en apariencia acaban, pero que tienen largas secuelas de rencor, de dolor e injusticia, sin que se pueda definir de forma clara un límite que pueda representar otro comienzo. Las prácticas de justicia transicional interesan, precisamente, porque proponen una discontinuidad entre un antes y un después, para que pueda haber un nuevo comienzo caracterizado por el pacto de reconciliación, destinado a convertirse en el sentido mismo de la nueva comunidad.

Un acontecimiento específico nos empuja a reflexionar sobre este argumento: en este período, mientras la revista se está editando (octubre de 2016), se realiza el referéndum en Colombia para ratificar la validez de los acuerdos de justicia transicional alcanzados después de una larga negociación de paz entre los grupos armados guerrilleros y el Estado de Colombia. Se trata de un conflicto infinito e inacabado, sin que podamos decir que esos grupos de guerrilla armada hayan sido derrotados de manera definitiva; de un conflicto, pues, que solo puede acabar por medio de un acuerdo de negociación.

Solo es uno de los muchos casos de justicia transicional que se están imponiendo en países y situaciones diferentes para poner punto final a largos y muy sangrientos conflictos internos en la comunidad; sin embargo, esta revista, que se publica en Bogotá, quiere ser útil al resultado del referéndum con los medios que posee una revista científica: reflexionando críticamente sobre los conceptos de conflicto-mediación-reconciliación, para dar cuenta tanto de las eventuales problemáticas teórico-jurídicas como de la transformación del concepto de mediación que se pone en práctica. Es aquí donde quisiéramos que se reflejara, para poder destacar la novedad del método empleado.

Está claro que en este caso -así como en los demás de justicia transicional- no se trata de la mediación conciliativa de tipo hegeliano que preside todas las visiones del progreso dialéctico y las teorías clásicas del desarrollo. En aquella perspectiva, lo negativo y el conflicto representaban la etapa "superada" -la Aufhebung hegeliana- a través de la hipótesis de la contradicción en el nuevo estadio evolutivamente más maduro. Este tipo de mediación dialéctica implica una conciliación sustancial y una asimilación de hecho. Ni siquiera se trata de la pretensión, por mucho tiempo sostenida por el cosmopolitismo jurídico, de tipo kantiano y universal, por la cual la conciliación se realiza subsumiendo el particularismo de las facciones en la universalidad

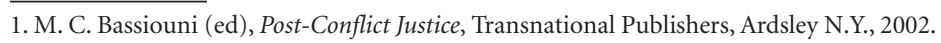


de la ley². Consideramos que estas dos formas clásicas de mediación que pertenecen a nuestra cultura moderna occidental no sirven para explicar la realidad actual. La conciliación dialéctica y el universalismo racionalista jurídico implican que la "razón" le gane la partida a lo negativo, al otro, sometiéndolo no solo al reconocimiento, sino también a la pertenencia al universo racional de los vencedores. Sabemos que la violencia presente en aquellos dispositivos, en apariencia, neutrales y racionales ha sido deconstruida; esto es, la homologación forzosa que, sobre la base de la razón universal histórica o abstracta que justifica al vencedor, atañe a las historias de los perdedores, borrando las heridas del camino y la diferente perspectiva de las partes en su singularidad.

En las experimentaciones actuales no faltan algunos importantes aspectos que remiten a este tipo de mediación/conciliación en nombre de la razón universal o de los derechos humanos. Sin embargo, queremos subrayar más bien la novedad de los procesos de justicia transicional que no son simplemente la aplicación jurídica de los derechos humanos y la sanción de las violaciones; una novedad, pues, que afirma con claridad la discontinuidad respecto de un discurso de verdad único y unificante.

De hecho, estos procesos entran en la lógica gubernamental de soft power, que presta apoyo y sustituye la pura verticalidad de los procesos de subsunción jurídica clásicos. En este caso, la mediación no entra en el diálogo de tipo habermasiano que, por fortuna y al final, se instauraría entre las partes convertidas en agentes simétricos y recíprocamente respetuosos y que, después de argumentaciones racionales, proporcionaría una deliberación justa y compartida. En este caso, la mediación es negociación, donde las partes mueven sus vectores de fuerza y de razón en el ámbito de las prácticas y de la transacción compromisoria, decidiendo una serie de temas que, a nivel moral y meramente jurídico, no se podrían decidir. Es la urgencia de la paz, y no la verdad adquirida, la que sostiene la negociación a través de innumerables obstáculos, y que sustituye la imposibilidad de decidir la cuestión lógico-jurídica. De hecho, quedan satisfechas -de forma negociada, parcial- las exigencias de compensación, los pedidos de satisfacción psicológica, moral, las necesidades de retribución.

Una parte fundamental de esas prácticas es la explicitación de las diferentes narraciones que han marcado algunos comportamientos y elecciones, y que han llevado a sufrimientos de por sí imperdonables. Las historias, las autoconfesiones, en su concreción y en la diversidad de perspectivas que proporcionan -en lugar de la serie de criterios

2. Cfr., en 1998, la institución de la Corte Penal Internacional (CPI) de La Haya, respecto de las violaciones de los derechos humanos, consideradas graves tanto como crímenes internacionales. 
abstractos y normas del derecho penal internacional-, representan el eje de estas prácticas de una justicia diferente.

Por otra parte, ¿qué hay que hacer cuando se quiere acabar el choque violento y de por sí interminable entre dos grupos, para dar comienzo al proceso de reconstrucción de un país? ¿Cómo cabría juzgar las violencias heredadas del pasado?

Está claro que estos temas se pueden discutir partiendo de la codificación de criterios generales y abstractos de evaluación que permitan determinar las responsabilidades individuales de las graves violaciones de los derechos humanos de los crímenes de guerra y contra la humanidad perpetrados durante el choque 3 . Sin embargo, lo más importante sería hacer emerger y entender las dinámicas sociales que han convertido en real, concreto e interminable ese conflicto, a través de los discursos verídicos de acusadores y acusados. La comprensión y el reconocimiento de la complejidad de lo que ha ocurrido son pasajes necesarios para saldar las cuentas con un período que, de lo contrario, parecería acabado solo cronológicamente. Enfrentar los fantasmas del pasado significa trabajar para un futuro de paz y cooperación entre las partes que integran la sociedad ofendida y traumatizada política, económica y psicológicamente.

Desde un punto de vista conceptual, cabe, pues, verificar los límites y condiciones de los modelos de la deliberación democrática concretos y no abstractos, que dan lugar a la formación de las instituciones del nuevo Estado; y se trata de solucionar la antigua cuestión de quién debe ser juzgado por quién y de cuáles pueden ser los costes de la fase de reconstrucción.

Detrás de esas deliberaciones, que funcionan fatigosamente por medio de procesos aletargados que deben declarar antes la verdad de los hechos que la lógica jurídica, están las prácticas realizadas por comisiones y tribunales que generan derecho, que someten los principios a la adaptación a las circunstancias. En esta actividad jurisdiccional no cuenta realmente el derecho codificado, sino más bien la pareja conceptual de nuestro tiempo: ética (perdón, la imposibilidad y la necesidad de un perdón gratuito e incondicional) y economía (dispositivos prácticos y estratégicos dirigidos al problem solving, por medio de actos de negociación, sin ninguna pretensión de lo justo, pero sí estimulados por la urgencia de lo conveniente, de lo necesario para la seguridad y el desarrollo de la vida).

3. Naciones Unidas, Consejo de Seguridad, The rule of law and transitional justice in conflict and post-conflict societies, Informe del Secretario General al Consejo de Seguridad, 23 de agosto de 2004, S/2004/616. 
Para Ricoeur, el perdón -la increíble práctica que se refiere a un pasado de dolor que no se borra- desata al agente de su acto ${ }^{4}$, purifica al titular de la acción malvada no solo de los efectos de su acción, sino más bien del acto como tal, como si el acto no le atañera o no se hubiera realizado nunca. Es una práctica imposible, pero de alguna manera necesaria para poder -arendtianamente- dar comienzo a algo nuevo. Por ejemplo, si el objetivo de la Comisión para la Verdad y la Reconciliación instituida en Sudáfrica al finalizar el apartheid, por un lado, era evitar-después de haber puesto punto final a la injusticia y a la violencia del régimen blanco- una rendición de cuentas violenta y sangrienta, además de una interminable y terrible guerra civil, y por otro lado, construir una nueva sociedad sudafricana basada en el perdón concedido por las víctimas a sus verdugos, este objetivo se podía alcanzar solo alejando las confesiones y los discursos verídicos de la lógica de la compensación justa 5 . Con relación al dolor, se estimula aquella forma de perdón que Arendt define como capacidad de olvidar que, a su vez, el dolor tiene relación con el agente que lo ha proporcionado. Se trata de una forma de perdón/ olvido que corta las cadenas de venganza y de dependencia del mal que, de lo contrario, se volvería a repetir.

Pero todo esto no puede convertirse en "derecho", no se puede imponer como regla general; por lo tanto, junto con la frágil dimensión ética de un perdón caracterizado por memoria y olvido, se ponen en práctica técnicas solo parcialmente jurídicas, de transacción, de negociación, que subyacen a una lógica económica, funcional, adaptativa y dirigida a optimizar el proceso de pacificación y el ajuste de cuentas, sin ninguna pretensión de totalizar la justicia y la retribución, que remiten más bien al criterio de lo oportuno, de lo conveniente, de lo eficaz.

Esta mezcla sin síntesis del gesto ético imposible y revolucionario ${ }^{6}$ de los dispositivos opacos, pero eficaces de la negociación pluriforme y multinivel hoy día tienen un radio de acción nunca antes visto. La necesidad de gobernar situaciones sin vías de escape y jurídicamente imposibles de decidir da lugar a intervenciones inéditas, en las que lo público y lo privado se confunden: el perdón sobrepasa la esfera de la moral íntima y privada para acabar invadiendo el ámbito de las instituciones políticas, convirtiéndose en el lugar en que se realiza la nueva vida de la comunidad histórica traumatizada, lacerada. De esta manera, el objetivo principal -que atañe a la superación no violenta de odios y enemistades profundas e inmemoriales- encuentra una solución lo

4. P. Ricoeur, La mémoire, l'Histoire, l'oubli, Seuil, Paris, 2000, p. 637.

5. Truth and Reconciliation Commission of South Africa, Report, 5 vols., vol. 1, Juta Publishers, Cape Town, 1998.

6. J. Derrida, "La siècle et le Pardon", en Le monde des débats, 9 de diciembre de 1999; ahora en id., Foi et Savoir, Seuil, Paris, 2000, p. 114. 
suficientemente duradera y compartida y, sobre todo, puede generar una forma inédita de estar-juntos. Pero repetimos que esto puede ocurrir si este gesto de perdón no se confunde con las mediaciones que, del ideal regulativo de tipo kantiano a la recomposición dialéctica de Hegel, tienden a reconstruir una trama continua de racionalización triunfadora y justa que solo alimentaría el rencor de los perdedores y de las víctimas obligadas a callar. En cambio, es necesario subrayar una discontinuidad a su manera revolucionaria, un milagro de reanudación, que rompe el régimen de comparabilidad abstracta que reglamenta las instituciones jurídicas. Este núcleo ético y discontinuo es el único capaz de dar sentido e identidad a la nueva comunidad. Precisamente por la naturaleza ética indeducible de este perdón, por su imposibilidad lógica, este núcleo no se puede trasladar al discurso jurídico habitual caracterizado por equivalencias y simetrías entre culpa y pena; solo puede basarse en una detallada, pormenorizada, incesante mediación de la cantidad de ofendidos y ofensores. Sabemos que estos no pertenecen a una sola de las facciones (sabemos que a la violencia de las FARC le corresponde la violencia de las organizaciones paramilitares y los excesos de las mismas fuerzas regulares). Ética y negociación eficaz son una pareja típica del soft power que gobierna la complejidad, presentando también debilidad y contradicciones.

Dentro de los artículos que leeremos a continuación, se profundizará en los criterios y las formas de justicia dirigidas a la comprobación de la verdad, lo que nos permitirá detenernos en la relación que los dispositivos de justicia transicional tienen con los discursos de verdad y su comprobación. Tal y como ya hemos dicho, para reglamentar situaciones complejas e indecidibles, la justicia tiene prevalencia jurisdiccional, como frente a un tribunal ad hoc o a una comisión de encuesta. Una comprobación judicial de la verdad respecto de los crímenes cometidos es indispensable para una efectiva pacificación y reconciliación nacional, puesto que llevará a una indemnización por lo menos moral de las víctimas y, al mismo tiempo, a la construcción de una memoria colectiva, bastante compartida, de los horrores del pasado, precisamente gracias a la narración que destacará del proceso. Se evidencia la relación de la verdad con el poder; cabe establecer una narración compleja y articulada, para que tenga el poder de comprometer a los diferentes puntos de vista sin sacrificar el dolor de las víctimas de cualquier parte.

Ya que se trata de narraciones que atañen a diferentes puntos de vista y recíprocamente contrastantes, hablamos de una comprobación de verdad que, a pesar de hacer hincapié en la responsabilidad, debe adoptar un matiz que permita poner remedio a la herida social. La finalidad prevaleciente es la reconciliación: restablecer la cohesión social, poniendo remedio a un sistema judicial fragmentado y construyendo un sistema 
de gobierno democrático. Es necesario que la verdad comprobada, junto con el núcleo ético del perdón, se protejan como enlace imprescindible para la nueva comunidad.

Tal y como ya hemos dicho, no consideramos la pura construcción jurídica que de los derechos violados (el derecho a la vida, a no sufrir torturas o desaparecer totalmente; el derecho a la libertad de expresión, a la comida, al trabajo, a la salud, incluso a la autodeterminación formalmente reconocidos durante los últimos sesenta años en documentos de valor jurídico) hace derivar el sistema penal de sanciones e indemnizaciones; palabras como reconciliación, refundación de la cohesión nacional, demuestran que se trata de un dispositivo jurídico nuevo en el cual se mezclan principios éticos cuya dimensión se prohibiría con técnicas y prácticas de tipo funcional guiadas por una lógica económica típica del soft power; unas prácticas, pues, que se miden más en términos de eficacia que de justicia ${ }^{7}$.

Con este número, vamos a abrir un laboratorio sobre las formas de mediación negociada para gestionar situaciones políticas complejas y, a menudo, indecidibles. Volveremos a hablar de eso en las páginas de esta revista. Otros ensayos presentes en este número proporcionan nuevos materiales a los demás ámbitos de reflexión abiertos por Soft Power: el del neoliberalismo, el de las formas de administración y gobierno que cada vez menos se pueden remitir a los clásicos principios del Estado de derecho moderno y, finalmente, el de la supuesta disminución de las mediaciones en las nuevas formas políticas de populismo.

Traducción del italiano de M. Colucciello

\footnotetext{
7. El actual significado de reconciliación está relacionado con el trabajo desarrollado en Sudáfrica por la Comisión para la Verdad y Reconciliación (CVR), instituida en 1995 para los crímenes cometidos bajo el régimen del apartheid entre 1960 y 1994. El objetivo de la Comisión era "promover la unidad nacional y la reconciliación en un espíritu de comprensión que sobrepase los conflictos y las divisiones del pasado [...]" (NURA, 1995, art. 3,1). La Comisión participaba en "el proceso de construcción de puentes dirigido a alejar la nación de un pasado caracterizado por divisiones profundas, para llevarla a un futuro basado en el reconocimiento de los derechos humanos y de la democracia (Informe CVR, 1998, 1, 48). Cfr., South African Government Gazette, Promotion of National Unity and Reconciliation Act No 34 (the Act) of 19 July 1995 ; Institute for Justice and Reconciliation (IJR), South African Reconciliation Barometer. Eight Round 2008, Institute for Justice and Reconciliation, Rondebosch, 2008. Véase también la Comisión Peruana de la Verdad, sobre los crímenes cometidos por el Estado peruano y por los grupos rebeldes y las organizaciones paramilitares, en los años 1980-2000: "un proceso de re-instauración y reformulación de los vínculos fundamentales entre ciudadanos peruanos; unos vínculos, pues, que han desaparecido o se han deteriorado en el conflicto de las últimas dos décadas" (Informe Comisión de Verdad y Reconciliación de Perú (CVR), Informe final, 2003, p. 346).
} 